\title{
Developing a comprehensive GIS tool to evaluate representative parameters regarding life comfort
}

\author{
Cristian-Gabriel Alionte ${ }^{1}$, Dana Rizescu $^{1, *}$, and Ciprian Ion Rizescu ${ }^{1}$ \\ ${ }^{1}$ University POLITEHNICA of Bucharest, Department of Mechatronics and Precision Mechanics, \\ RO-060042, Splaiul Independentei, 313, sector 6, Bucharest, Romania
}

\begin{abstract}
In this paper, we present a tool dedicated to assessing life quality according to the notion of comfort which can link three aspects of noise, light, and air pollution with two aspects of thermal and odour discomfort because the beforementioned aspects are using different calculation methods of the parameters which are distinct and some of them are defined in the national or EU legislation. The authors developed a compressive database to evaluate representative quantities of energy loses. There were considered some performance indicators as: energy class, total specific energy consumption, $\mathrm{CO} 2$ equivalent emission index, the overall heat transfer coefficient of the building and characteristic temperatures, the corrected number of degrees days, and the duration of the heating season at locality level.
\end{abstract}

\section{Introduction}

The term quality of life is a complex and multidisciplinary term [1] and, for this reason, it is difficult to identify and establish measurement parameters although there is a great lot of interest in constantly improving the quality of life in the European Union. But the factors affecting the quality of life in the environment are known [2] and are being linked in particular to the health of the person or offering sustainable welfare so they are related to the environment in which they live, and they are transformed into a simple notion of comfort/discomfort.

The software tools used for calculation are based on Geographical Information System (GIS) used for managing, analysing, and storing data and associated attributes which are spatially referenced to a specific Earth coordinates [3] recognized by each nation by legislation. For Romania can be used two different geographic coordinate systems Stereo70 and ETRS89 according to Order of the Minister for Environment and Sustainable Development No. 1830/2007 for the approval of the Guide on the production, analysis, and evaluation of strategic noise maps [4] and can be used also for thermic assessment, light, and air pollution.

The GIS data can be graphical features and attribute data, with relational patterns between them over time and space [5]. GIS data are simplified representations of real

* Corresponding author: dana.rizescu@upb.ro 
objects which can be discrete (buildings, fences, roads, point source, line source) or continuous fields (land use, elevation, waterways, etc.).

For the pollution calculation vector images (containing points, lines, or polygons) are used and, for representation support, raster images are used. The vectors are used to model the sources and obstacles and continuous fields are used to model the environment and the surfaces (the terrain or the land use). Also, several internal calculation methods for dispersion, absorption, and path calculation can be applied to individual objects or to summarize calculation or can be used external software for calculation (e.g., R code).

The output can be graphical (raster images) where are presented the level of pollution in colour scales or statistical where are presented the affected persons. In the following chapters we will present some of the specific parameters for acoustic comfort, air quality, and energy performance.

\section{Acoustic comfort}

Acoustic comfort is defined in terms of annoyance [6] and sleeps disturbance [7]. The $\mathrm{L}_{\mathrm{den}}$ which is indicator of annoyance and $\mathrm{L}_{\text {night }}$ used for sleep disturbance are legislated by Environmental Noise Directive (END 2002/49/CE [8]) and are individually assess for four source types through modelling. In the table 1 is presented each standard defined for modelling in Romania according to the Government Decision 321/2005 with amendments and additions [1] which transposes the END 2002/49/CE [7].

Table 1. Setting Word's margins.

\begin{tabular}{|l|l|}
\hline Noise source/type & Method \\
\hline Road & $\begin{array}{l}\text { NMPB Routes-96 (SETRA-CERTU-LCPCCSTB), French } \\
\text { Standard XPS 31-133 [9] }\end{array}$ \\
\hline Railway & Dutch SRM II - 1996 [10] \\
\hline Aircraft & ECAC.CEAC Doc. 29 [11] \\
\hline Industrial & $\begin{array}{l}\text { ISO 9613-2 - Acoustics - Attenuation of sound during } \\
\text { propagation outdoors - Part 2: General method of calculation } \\
{[12]}\end{array}$ \\
\hline
\end{tabular}

For the noise calculation, it can be used some specialized software based on GIS software: CadnaA, IMMI, SPM9613 Community Noise Prediction, CUSTIC, Predictor-LimA Software Suite Type 7810, Acoustic Determinator 7816, MITHRA SIG, SoundPLAN [3].

The formula (1), used for $\mathrm{L}_{\mathrm{den}}$ is [9]:

$$
L_{D E N}[d B]=10 \lg \frac{1}{24}\left(12 \cdot 10^{\frac{L_{d a y}}{10}}+4 \cdot 10^{\frac{L_{\text {evening }}+5}{10}}+8 \cdot 10^{\frac{L_{n i g h t}+10}{10}}\right)
$$

$\mathrm{L}_{\text {day }}, \mathrm{L}_{\text {evening, and }} \mathrm{L}_{\text {night }}$ are statistic factors which mediate all the noise for 12,4 and 8 hours of the day between 07:00-19:00, 19:00-23:00, and 23:00-07:00.

One of the problems consists in that the noise assessment considers only separate sources not the effect of all sources because when the noise level is exceeded the competent authority can implement a solution for noise abatement. In this way, the whole problem of the noise is not solved.

\section{Air quality and odour discomfort}

The smell sense is a mechanism which aid human survival because protect the human from noxious gases and must be quick and sensitive. But a correlation between sensitivity of an odour and relevance because information regarding the olfactory sensitivity is limited and 
depends on person to person. Therefore, another approach must be made and was introduced the notion of air quality. According to the Romanian legislation, the air quality assessment is done using long-time measurements (monitoring) according to Law no. 104/2011 [15]. But using monitoring gives us only punctual values so it can be used calculation air dispersion models to provide information regarding the spatial distribution of the quality of air. For example, it can be used a simple Gaussian dispersion model based on Gaussian plume distribution [27] is described by relation (2) based on the model presented in figure 1:

$$
c=\frac{Q}{2 \pi \sigma_{y} \sigma_{z} u} e^{\frac{-y^{2}}{2 \sigma_{y}^{2}}}\left(e^{\frac{-(z-h)^{2}}{2 \sigma_{z}^{2}}}+e^{\frac{-(z+h)^{2}}{2 \sigma_{z}^{2}}}\right)
$$

where:

$c$ - concentration at a given position on field $\left(\mu \mathrm{g} \cdot \mathrm{m}^{-3}\right)$,

$Q$ - the source power (grams),

$x$ - the downwind $(\mathrm{m} / \mathrm{s})$,

$y$ - the crosswind $(\mathrm{m} / \mathrm{s})$,

$z$ - the vertical direction $(\mathrm{m})$,

$u$ - the wind speed $(\mathrm{m} / \mathrm{s})$,

$h$ - the height of the release[m].

The $\sigma_{y}, \sigma_{z}$ deviations describe the vertical mixing of the pollutant which depend on atmospheric stability.

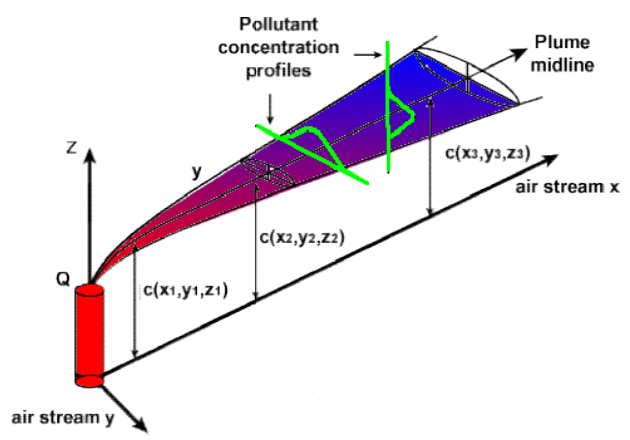

Fig. 1. Gaussian plume distribution model [27]

\section{Developing a comprehensive database to evaluate representative quantities regarding energy losses}

The building energy performance is starting to consider some performance indicators:

- energy class;

- total specific energy consumption;

- $\quad \mathrm{CO} 2$ equivalent emission index;

- the overall heat transfer coefficient of the building;

- characteristic temperatures, the corrected number of degrees days, and the duration of the heating season - at locality level

The application of these parameters in Romania has a great interest because of the great potential [17]. It is known that in South-East Europe (Romania, Bulgaria, Czech, Hungary, Moldova, Poland, Slovakia, etc.) had similar buildings development plans during the last 60 years. An example is the blockhouses developed in the two countries. There were used similar designs, technologies, materials, and plans. Unifying the present rules of building 
construction and keeping the local apprentice at the same time is one goal. The outcomes of this approach will be a recommendation for local authorities to authorize those technologies which make the best thermal isolation of the buildings with fewer costs and lower fuel consumption per square meter for maintaining indoor air quality. If you want to heat or cool the indoor, energy transfer from indoor to outdoor is a key factor. To uptake the new or improved technologies to reduce or to prevent energy waste, also, reducing the use of hazardous materials in building sector concerning environmental and social ethics conduct the idea to find new assessment tools. For that, the steps are pre-normative research on thermal building expertise, building investigation by thermo-vision, uptake database from local authorities, and develop a comprehensive database to evaluate representative entities regarding energy losses. This method needs gathering data from existing local administration, based on energy consumption levels and architectural or construction structures, considering all types of dwelling. The heterogeneous distributed data that concern different aspects of energy utilizing for heating and cooling of buildings will be considered, organized, and classified in an ontological manner. To build the database is also need:

1. Data collection on building construction and orientation for different types of dwelling units.

2. Collection and evaluation of climatic data.

3. Creation of domain ontology for the semantic description of the data regarding energy loses

4. Analysis of semantic differences for the data from different sources such as local info, thermo-vision expertise, information of the construction structures, and support of interaction under different data schemes for the heterogeneous distributed data

5. Investigate the possibilities of including thermal insulation, double glazed windows to reduce heat transfer indoors outdoor.

The procedure must include the assessment and improvement of the environmental, economic, and institutional impacts of technologies on buildings efficiency and normative proposal elaboration with technical and nontechnical barriers concerning directive 2002/91/EC. Also, must be used models for describing heterogeneous data concerning building construction, orientation, climatic data, building enveloping methods, and thermovision.

Thermo graphical and data achievement on a building should respect the existing specifications of EU standards and recommendations as EN ISO/CEI 17025:2005 [19] and ENV ISO 13005:2005[20], that guide the ways of data acquiring, processing, inference, and, finally, decision making according to a certain trusting degree on building efficiency. Based on the beforementioned conditions we made a database that is considered one parameter: the energy class of the building: energy class of the building.

\section{Light pollution}

Light pollution is unwanted artificial lighting, and it has negative impacts on humans and animals [20]. This type of pollution leads to an increased risk of breast cancer in women since the obtrusive light disturbs the production of melatonin which keeps people from falling into a deep sleep [22]. Also, light pollution can have a significant impact on urban air quality because light pollution breaks down NO3 via photolysis (which is destroyed by sunlight) which serves to cleanse the atmosphere and mitigate the ozone and other atmospheric pollutants. [22]. 
One method for modelling light pollution is to use fractional logit regression. For this the model assumes that the light sources are points. For the receiving point can be used the equation [23]:

$$
X \beta=\ln \left(\frac{D}{1-D}\right)
$$

where $X$ is the observation matrix of lighting variables and $\beta$ is the vector of estimated coefficients.

The disadvantage of using this model is that of lost observations. The least number of observations are lost for those light pollution measures with more moderate threshold values.

\section{Experimental results}

For the calculation of the pollution parameters, we used QGis [23], Noise Modelling [25], and $\mathrm{R}$ code [26]. We build the model using Open Street Map [27]. The source input emission data was measured or estimated. The calculation was performed only for educational purposes. After the calculation, we have the following results.

For the noise map it was built a model for the noise maps road traffic, railroad traffic, and industry, using the definitions and the assessment methods specified in END 2002/49 /EU [8] for Lden and Lnight, figure 2.

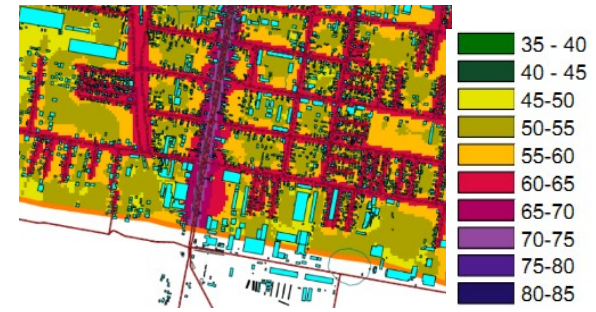

Lden for road source $[\mathrm{dB}]$

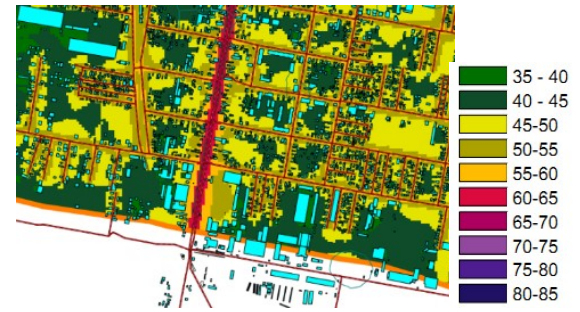

Lnight road source $[\mathrm{dB}]$

Fig. 2. Road noise pollution

For the odour/air pollution, it was used the Gaussian plume dispersion method. The roads were divided into segments, and after that in points that represents the pollution sources. After that, a grid of points was build which represent the calculated receivers, and for each receiver, it was calculated the distance from each source. The matrix of distances was built and introduced in $\mathrm{R}$ code to calculate the dispersion using the equation of Gaussian plume model for each source, figure 3.
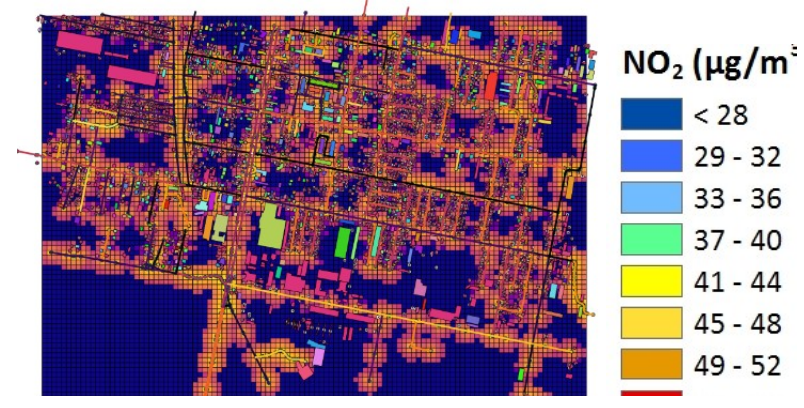

Fig. 3. The air pollution map 
For each building it was found the center which took the value of the receiver point, so each building is becoming a receiver, figure 4 .

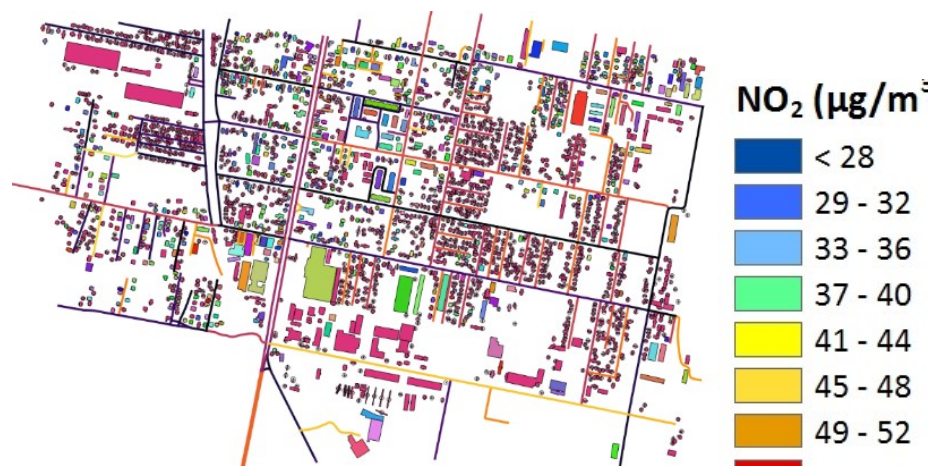

Fig. 4. Air pollution calculated for each building

An important part of solving the problem of light pollution is to have a thorough understanding of its magnitude, and a great way to do that is to measure the brightness of the night sky. It is known that creating and controlling light is a great engineering achievement. Engineers develop artificial sources of light to satisfy specific requirements including good luminance, energy savings, and light fixture design that appropriately directs and reflects light, reduces light waste, and minimizes light invasion. The modern complexity of light installation in buildings and outdoor venues requires the expertise of lighting/illumination engineers to design for specific needs and optimize power consumption.

The same method, but using fractional logit regression was used to calculate the light pollution. The results are presented in figure 5 .

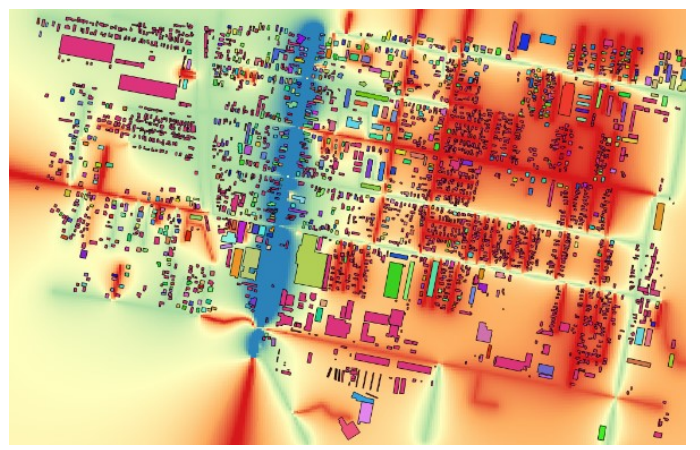

Fig. 5. Light pollution calculation in lux (blue $-75 \%$ pollution, yellow $-50 \%$ pollution, red - dark zone) 


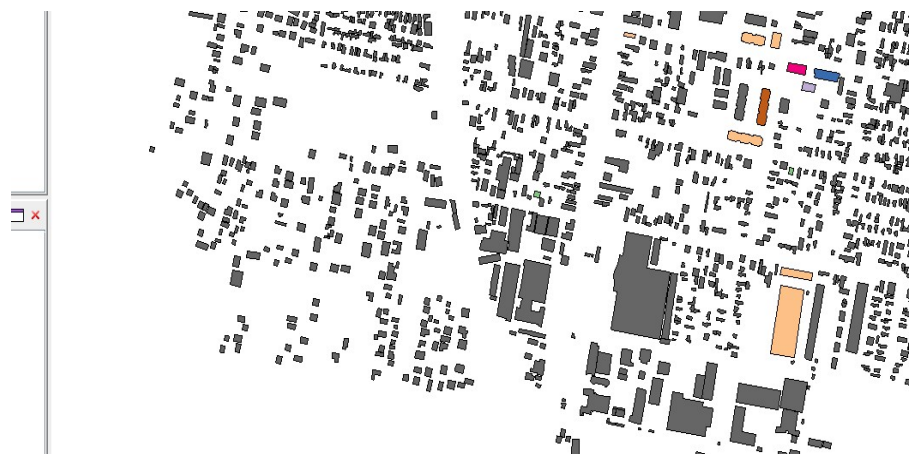

Fig. 6. Thermo vision analyses

Energy performance indices are used around the world to evaluate and monitor residential and commercial building energy performance during design, construction, renovation, and operation. The two most common indices are Asset Ratings and Operational Ratings. Asset Ratings are based on modelled energy use with uniform conditions of climate, schedules, plug loads, occupancy, and energy management.

For building energy performance was introduced the energy class as a building attribute. The calculation method was based on thermo-vision and on building construction material, figure 6 .

\section{Conclusions}

The paper presents a tool dedicated to assessing life quality according to the notion of comfort which can link three aspects of noise, light, and air pollution with two aspects of thermal and odour discomfort because the beforementioned aspects are using different calculation methods of the parameters which are distinct and some of them are defined in the national or EU legislation. Also, the authors developed a compressive database to evaluate representative quantities of energy loses based on the specific parameters for: acoustic comfort, air quality, and energy performance. There were considered some performance indicators as energy class, total specific energy consumption, $\mathrm{CO} 2$ equivalent emission index, the overall heat transfer coefficient of the building and characteristic temperatures, the corrected number of degrees days, and the duration of the heating season - at locality level. Countries from Central and East Europe: Romania, Bulgaria, Czech, Hungary, Moldova, Poland, Slovakia etc. have similar buildings developed in the last 60 years. The database, depending on the geographical coverage, will be developed by each country from the project. Each country will consider how many areas are covered, where, and how many sources, how many receivers will be placed. These data can also be provided at the internet address where these results can be consulted. This new database could be developed in the frame of bilateral projects as well as regional projects.

\section{References}

1. R. Keles, The Quality of Life and the Environment, Social and Behavioral Sciences 35 23 - 32, Asia Pacific International Conference on Environment-Behavior Studies, Salamis Bay Conti Resort Hotel, Famagusta, North Cyprus, 7-9 December 2011, (2012). 
2. N. Görer, and A. Ushowl, An Essay on the Quality of Life and Indicators of the Quality of Urban Life), Localism and Politics: In Honour of Rusen Keles ImagePublishers, Ankara, pp.225-234, (2007).

3. A. Petrovici, C. Tomozei, R. Gey Flores, F. Nedeff, O. Irimia, Noise prediction, calculation and mapping using specialized software, Journal of Engineering Studies and Research - Volume 21, No. 3, (2015).

4. OM MMDD no. $1830 / 2007$

5. S. Rao, and K. Jayasree, Dynamic Geographic Information System for Intelligent Traffic Guidance Systems, Geosciences and Remote Sensing Symposium 2005, Proceedings. IEEE International, (2005)..

6. J.Y. Jeon, P.J. Lee, J.H. Kim, et al. Subjective evaluation of heavy-weight floor impact sounds in relation to spatial characteristics. J Acoust Soc Am; 125(5): 2987-2994, (2009).

7. G. Belojevic, V. Slepcevic, B. Jakovljevic - Mental performance in noise: The role of introversion, June 2001, Journal of Environmental Psychology 21(2):209-213

8. European Directive 49/2002 (ED 2002/49, 2002)

9. HOTĂRÂRE nr. 321 din 14 aprilie 2005 republicată și actualizată până la data de 28 decembrie 2016 privind evaluarea şi gestionarea zgomotului ambient

10. CERTU, CSTB, LCPC, and SETRA. Bruit des Infrastructures Routières: Méthode de Calcul incluant les Effets Météorologiques, Version Expérimentale NMPB-Routes-96; J. Off. du 10 mai 1995, Artic. 6o French Stand. 'XPS31-133'; Cetur-Centre Etud Transp: Alairac, France, p. 98, (1997).

11. Reken - en Meetvoorschrift Railverkeerslawaai '96, Ministerie Volkshuisvesting, Ruimtelijke Ordening en Milieubeheer, 20 November (1996).

12. https://www.ecac-ceac.org/images/documents/ECAC-

ANCAT_Guidelines_Noise_Measurement_Homebuilt_Aircraft_2013.pdf [Accessed 19.05.2021]

13. Law no. 104/2011 - http://legislatie.just.ro/Public/DetaliiDocument/129642 [Accessed 19.05.2021]

14. R. Bhattacharya, Atmospheric https://ansn.iaea.org/Common/Topics/OpenTopic.aspx?ID=13012 19.05.2021]

15. https://tk.elte.hu/dstore/document/1133/energiafoldrajz\%20tankonyv.pdf [Accessed 19.05.2021]

16. S.D. Cîrstea, C. S. Martis, A. Cîrstea, A. Constantinescu-Dobra and M. Timea Fülöp, Current Situation and Future Perspectives of the Romanian Renewable Energy, Energies, 11, (2018).

17. ISO/IEC 17025:2005- General requirements for the competence of testing and calibration laboratories, https://www.iso.org/standard/39883.html [Accessed 19.05.2021]

18. ENV 13005 Guide on Uncertainty in Measurement (GUM) https://boss.cen.eu/media/CEN/ref/cen_13.pdf [Accessed 19.05.2021]

19. C. Rich, and T. Longcore, Ecological Consequences of Artificial Night Lighting. Washington DC: Island Press, (2006).

20. K.J. Navara, and R. J. Nelson. "The Dark Side of Light at Night: Physiological, Epidemiological, and Ecological Consequences." Journal of Pineal Research 43: 215 224, (2007). 
21. H. Stark, S. S. Brown, W. P. Dube, N. Wagner, T. B. Ryerson, I. B. Pollack, C. D. Elvidge, D. Ziskin, and D. D. Parrish. "Nighttime Photochemistry: Nitrate Radical Destruction by Anthropogenic Light Sources." American Geophysical Union Meeting, (2010).

22. O. Reed, T. Gallaway, D. Mitchell, Modelling US light pollution, Journal of Environmental Planning and Management 57(6), (2014).

23. https://www.qgis.org/en/site/? [Accessed 19.05.2021]

24. https://github.com/Ifsttar/NoiseModelling [Accessed 19.05.2021]

25. https://www.pgm-solutions.com/rcode [Accessed 19.05.2021]

26. https://www.openstreetmap.org/\#map=7/45.996/24.981 [Accessed 19.05.2021]

27. https://personalpages.manchester.ac.uk/staff/paul.connolly/teaching/practicals/material/ gaussian_plume_modelling/gp_notes.pdf [Accessed 19.05.2021] 